\title{
Is Acute Testicular Pain and Vomiting in a Pubertal Boy Pathognomonic of Testicular Torsion?
}

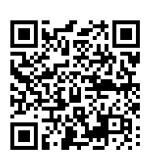

\author{
Aslam $\mathrm{A}^{1,2,4 *}$, Nason GJ ${ }^{3,4}$, Domanska $\mathrm{K}^{4}$, Durkan GC ${ }^{2,4}$ and Flood HD ${ }^{4}$ \\ ${ }^{1}$ Department of Urology, Letterkenny University Hospital, Ireland \\ ${ }^{2}$ Department of Urology, Galway University Hospital, Ireland \\ ${ }^{3}$ Division of Urology, Department of Surgery, Canada \\ ${ }^{4}$ Department of Urology, University Hospital Limerick, Ireland
}

Submission: January 08, 2019; Published: January 30, 2019

*Corresponding author: Asadullah Aslam, Consultant Urologist, Letterkenny University Hospital, Letterkenny, Co. Donegal, Ireland

\section{Introduction}

Testicular torsion (TT) is a urological emergency most commonly seen in adolescence, involving a decrease in blood flow in the testis resulting from torsion of the spermatic cord that can lead to gonad injury or even loss if not treated promptly [1]. TT has an annual incidence of 3.8 per 100,000 males younger than 18 years [2]. It accounts for approximately $10-15 \%$ of acute scrotal presentations in children and results in an orchidectomy rate of $42 \%$ of boys undergoing acute scrotal explorations $[3,4]$. Delay from the time of onset of pain until scrotal exploration is important for the chances of testicular salvage. Patients under the age of 14 years are typically associated with longer delays [5]. A lack of parental awareness of the potential sequelae of acute scrotal pain is a significant factor in delayed presentations of children to hospital [6].

Prompt presentation, diagnosis and management are important factors for testicular salvage and TT needs to be out ruled in all patients presenting with acute scrotum. TT is a clinical diagnosis however patients can present with a multitude of nonspecific symptoms associated with acute scrotal pain including nausea, vomiting and fever [7-10]. Classical signs on clinical examination such as an absent cremasteric reflex, a high riding, a horizontal lie is not always present, often unreliable and difficult to illicit $[9,10]$. Clinicians need to have a high index of clinical suspicion for TT in any patient presenting with acute scrotal pain. In patients with a history and physical examination suggestive of TT, imaging should not be performed, and immediate exploration is warranted [11]. If imaging is preformed, physical findings strongly suggestive of TT should be explored regardless of ultrasonic findings [12,13]. There is typically a four to eight-hour window before significant ischaemic damage occurs, manifested by morphological changes in testicular histopathology with negative implications for spermatogenesis [14]. The viability of the testes at exploration is difficult to predict- reported testicular salvage rates are 90-
$100 \%$ if explored within six hours of symptom onset, reducing to $50 \%$ if more than 12 hours and around $10 \%$ if symptom duration is more than 24 hours $[15,16]$.

The diagnosis of TT can be challenging given the broad differential diagnosis of the acute scrotum including TT, torsion of a testicular appendage, epididymitis, hydrocele and testicular tumor [17]. Numerous attempts have been made to develop scoring systems as predictors of TT however none are standard in clinical practice $[4,18]$. The aim of our study was to assess if vomiting associated with acute scrotal pain is a reliable predictor of TT.

\section{Methods}

A retrospective review of medical charts was conducted of all patients with acute scrotal pain who attended the Emergency Department of University College Hospital Galway (UCHG) and University Hospital Limerick (UHL) from $1^{\text {st }}$ Jan 2013 to $30^{\text {th }}$ Jun 2016. Patient demographics, pain onset and duration, pubertal status, clinical examination, time to transfer to theatre and operative findings were recorded. In both departments, it is not standard practice to request scrotal imaging on all patients with acute scrotum. All patients with acute testicular pain who underwent scrotal exploration were included in the study except for patients with testicular trauma, testicular tumor, scrotal or testicular abscess.

Scrotal exploration is performed in a standard fashion under general anesthesia through a midline scrotal incision. Intravenous co-amoxiclav is given at induction. Initially the affected testis is examined after opening the tunica vaginalis. If there was no evidence of testicular torsion, an orchidopexy is not performed and the contralateral testis is not examined. The dartos muscle is closed with absorbable $3 / 0$ Vicryl ${ }^{\circledR}$ suture and the skin is closed with absorbable 4/0 Vicryl Rapide $®$. If there is evidence of TT- the affected testes is untorted, examined, 
wrapped in warm soaked gauze swabs for 20 minutes and high flow oxygen adminstered. During this period, the contralateral testis is examined and a three-point lateral fixation performed with non-absorbable 4/0 Prolene $\AA$. Subsequently, the affected testis is re-examined. At this point a clinical decision is made as to the viability of the testis by the operating surgeon. If deemed viable, a similar orchidopexy is performed. If deemed nonviable, an orchidectomy is performed. Post-operatively, patients are given a scrotal support for one week. Bed rest is advised for 24 hours and limited activity for two weeks. Patients are discharged home when comfortable on oral analgesia, usually day 1 post operatively. All patients are seen in the outpatients at three months.

\section{A Negative Exploration was Defined as any Diagnosis other than TT at Exploration}

Our primary outcome was to assess if vomiting associated with acute scrotal pain was a predictor of testicular torsion. Statistical analysis was performed using SPSS 23.0. Predictive values and correlation between different variables were calculated using contingency tables, Chi-squared test, correlation coefficient and relative risk. Where applicable, data was presented with $95 \%$ CIs. A p-value of less than 0.05 was considered to indicate statistical significance.

\section{Results}

Table 1: Presenting Symptoms in all patients $(n=132)$.

\begin{tabular}{|c|c|}
\hline Clinical Finding & Number and Incidence \\
\hline Pain site & \\
\hline Left & $73(55 \%)$ \\
\hline Right & $59(45 \%)$ \\
\hline Duration of pain & $34(26 \%)$ \\
\hline$<6$ hours & $44(33 \%)$ \\
\hline $6-12$ hours & $40(30 \%)$ \\
\hline $12-24$ hours & $14(11 \%)$ \\
\hline$>24$ hours & $76(58 \%)$ \\
\hline Pubertal (<13years) & $28(21 \%)$ \\
\hline Abdominal pain & $37(28 \%)$ \\
\hline Vomiting & \\
\hline
\end{tabular}

During the study period, 548 patients presented to the Emergency Departments with acute scrotal pain. 150 underwent a scrotal exploration. Eighteen patients were excluded based on the exclusion criteria of trauma, infection or tumor. Complete

Table 3: Predictive factors in the diagnosis of testicular torsion. data was available for 132(85.7\%) patients undergoing scrotal exploration for suspicion of testicular torsion. 46(34.8\%) had evidence of testicular torsion at the time of surgery. 86(65.2\%) had a negative exploration. Intraoperative pathological diagnoses included torsion of a testicular appendage (Hydatid of Morgagni) in 64(49\%), epididymoorchitis in 20 (15\%) and obstructed inguinal hernia in $2(1 \%)$. The median age of patient undergoing scrotal exploration was 12.5 year (Range of 1-29 years). The presenting symptoms and time to presentation are described in (Table 1).

\section{Testicular Torsion Group}

Table 2: History, clinical and operative findings in torsion group $(n=46)$.

\begin{tabular}{|c|c|}
\hline Clinical Finding & Number and Incidence \\
\hline Mean age & $15 \mathrm{y}$ \\
\hline Pain site & $25(54 \%)$ \\
\hline Left & $21(46 \%)$ \\
\hline Right & \\
\hline Duration of pain & $18(39 \%)$ \\
\hline$<6$ hours & $10(22 \%)$ \\
\hline 6 to $\leq 12$ hours & $8(17 \%)$ \\
\hline 12 to $\leq 24$ hours & $10(22 \%)$ \\
\hline$>24$ hours & $38(83 \%)$ \\
\hline Pubertal/Adults & $35(76 \%)$ \\
\hline Vomiting & $1(2 \%)$ \\
\hline Abnormal dipstick & $24(52 \%)$ \\
\hline Tender testis & $9(20)$ \\
\hline Abdominal Pain & $39(85 \%)$ \\
\hline Abnormal Cremasteric Reflex & $27(59 \%)$ \\
\hline High riding testis & $32(70 \%)$ \\
\hline Erythema & \\
\hline
\end{tabular}

$46(34.8 \%)$ patients were found to have evidence of testicular torsion occurring most frequently in older boys who were pubertal or adults. The median age was 14 years (Range 8-29 years). $18(39 \%$ ) had pain duration of less than 6 hours, $10(22 \%)$ had pain between 6 to 12 hours, $8(17 \%)$ were symptomatic between 12 to 24 hours while $10(22 \%)$ had pain for more than 24 hours. 35 patients $(76 \%)$ had at least one episode of vomiting from the onset of symptoms ( $p<0.0001) .9(20 \%)$ patients had abdominal pain associated with testicular pain ( $p=0.735) .39$ $(85 \%)$ had absent cremasteric reflex $(\mathrm{p}<0.0001)$, (Table 2$)$.

\begin{tabular}{|c|c|c|c|c|c|c|}
\hline Clinical finding & Sensitivity $(95 \% \mathrm{CI})$ & Specificity $(95 \% \mathrm{CI})$ & $\begin{array}{c}\text { Positive predictive } \\
\text { value }(95 \% \mathrm{CI})\end{array}$ & $\begin{array}{l}\text { Negative predictive } \\
\text { value }(95 \% \mathrm{CI})\end{array}$ & $\begin{array}{c}\text { Correlation } \\
\text { coefficient }\end{array}$ & p-value \\
\hline $\begin{array}{l}\text { Acute testicular } \\
\text { pain }\end{array}$ & $98 \%$ (88.5 -99.9\%) & 3\% (18.7 -38.6\%) & $2 \%(38.7-45.4 \%)$ & $96 \%$ (77 -99.4\%) & 0.313 & $<0.0001$ \\
\hline $\begin{array}{c}\text { Abnormal } \\
\text { cremasteric reflex }\end{array}$ & $\%(71-93.6 \%)$ & $94.1 \%$ (87 -98\%) & $88.6 \%$ (76.7 -94.8\%) & $92 \%(85.4-95.8 \%)$ & 0.798 & $<0.0001$ \\
\hline Pubertal/Adult & $82.6 \%(68.6-92.2 \%)$ & $55.8 \%(44.7-66.5 \%)$ & $50 \%(43.2-56.8 \%)$ & $85.7 \%(75.6-92 \%)$ & 0.37 & $<0.0001$ \\
\hline High lying testis & $58.7 \%(43.2-73 \%)$ & $93 \%$ (85.4 -97.4\%) & $81.8 \%(66.7-91 \%)$ & $80.8 \%(74.8-85.6 \%)$ & 0.569 & $<0.0001$ \\
\hline
\end{tabular}


JOJ Urology \& Nephrology

\begin{tabular}{|c|c|c|c|c|c|c|}
\hline Erythema & $69.6 \%(54.2-82.2 \%)$ & $34.8 \%(25-46 \%)$ & $36.4 \%(30.8-42.2 \%)$ & $68.2 \%(56-78.3 \%)$ & 0.045 & 0.605 \\
\hline Tenderness & $52.2 \%(37-67.1 \%)$ & $47.7 \%(36.7-58.7 \%)$ & $34.8 \%(27.4-42.8 \%)$ & $65.1 \%(56.1-73 \%)$ & -0.001 & 0.987 \\
\hline Blue dot sign & $0 \%(0-7 \%)$ & $79.1 \%(68.9-87.1 \%)$ & $0 \%$ & $59.6 \%(57-62.2 \%)$ & -0.291 & 0.001 \\
\hline $\begin{array}{c}\text { Abnormal urine } \\
\text { dipstick }\end{array}$ & $2.2 \%(0.06-11.5 \%)$ & $94.2 \%(87-98.1 \%)$ & $16.7 \%(2.3-62.4 \%)$ & $64.3 \%(62.7-65.8 \%)$ & -0.083 & 0.915 \\
\hline Vomiting & $76.1 \%(61.2-87.4 \%)$ & $\begin{array}{c}97.6 \%(92 \%- \\
99.7 \%)\end{array}$ & $94.6 \%(81.5-98.6 \%)$ & $82.4 \%(82-92.7 \%)$ & 0.783 & $<0.0001$ \\
\hline $\begin{array}{c}\text { Vomiting in a } \\
\text { pubertal/adult } \\
\text { with torsion }\end{array}$ & $71.7 \%(56.5-84 \%)$ & $100 \%(95.8-100 \%)$ & $100 \%$ & $87 \%(80.6-91.3 \%)$ & 0.789 & $<0.0001$ \\
\hline
\end{tabular}

Sudden pain was present in 45 (98\%) out of 46 cases of TT. It had sensitivity of $98 \%$ (95\% CI: $88.5-100 \%)$, specificity of $28 \%$ (95\% CI: $18.8-38.6 \%$ ), positive predictive value of $42 \%$ (95\% CI: $38.7-45.5 \%$ ) and negative predictive value of $96 \%$ (95\% CI: 77-99.4\%). The accuracy was 52.3\%. The results were statistically significant at $\mathrm{p}<0.0001$, (Table 3 ).

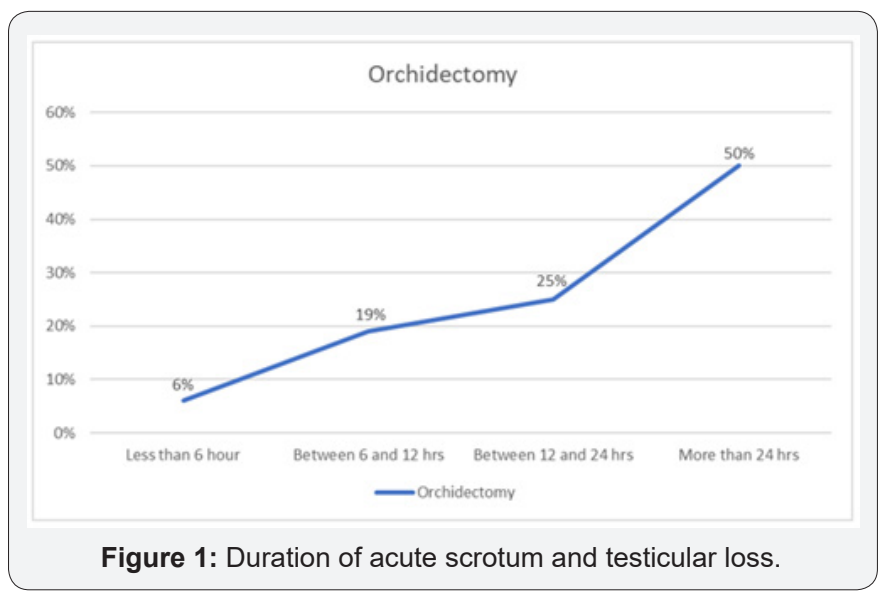

Cremasteric reflex was abnormal or absent in 39(85\%) cases of TT. This had sensitivity of $85 \%$ (95\% CI: 71.1-93.7\%), specificity of $94.2 \%(95 \% \mathrm{CI}: 86.9-98 \%)$, positive predictive value of $87 \%$ (95\% CI: 76.8 - 94.8\%) and negative predictive value of $92 \%$ (95\% CI: $85.4-95.8 \%$ ). The accuracy was $91 \%$. The results were statistically significant at $p<0.0001 .35$ (76\%) patients had at least a single episode of vomiting. It had sensitivity of $76 \%$ (95\% CI: $61.2-87.4 \%$ ), specificity of $98 \%$ (95\% CI: 91.8-99.7\%), positive predictive value of $95 \%(95 \%$ CI: $81.5-98.6 \%)$ and negative predictive value of $88 \%$ (95\% CI: $82-92.7 \%$ ). The accuracy was $90 \%$. The results were statistically significant at $\mathrm{p}<0.0001 .38(83 \%)$ out of 46 patients who had TT, were either pubertal or adults. This alone in the context of testicular torsion had sensitivity of $83 \%$ (95\% CI: $68.6-92.2 \%)$, specificity of $55.8 \%$ (95\% CI: 44.7-66.5\%), positive predictive value of $50 \%$ (95\% CI: $43.2-56.8 \%$ ) and negative predictive value of $85.7 \%$ (95\% CI:75.7-92\%). The accuracy was $65 \%$. The results were statistically significant at $\mathrm{p}<0.0001 .33(87 \%)$ boys who were pubertal or adults with acute scrotum also had at least a single episode of vomiting. This had a sensitivity of $69.6 \%$ (95\% CI: $54.3-82.3 \%$ ), specificity of $98 \%$ (95\% CI: $92-$ 99.7\%), positive predictive value of $94.1 \%$ (95\% CI: 80-98.5\%) and negative predictive value of $86 \%$ (95\% CI:70.5-90.3\%). The accuracy was $88 \%$. The results were statistically significant at $\mathrm{p}<0.0001$. Overall $16(35 \%)$ patients underwent orchidectomy, $1(6 \%)$ in less than 6-hour group, $3(19 \%)$ in 6-12-hour group, $4(25 \%)$ in $12-24$ hours group and remaining $8(50 \%)$ in more than 24-hour group ( $\mathrm{p}<0.0001)$, (Figure 1 ). The results were statistically significant $(\mathrm{p}=0.001)$. Median time from review by urology in the Emergency Department to theatre was $43 \mathrm{mins}$ (Range 25 - 55 mins). No significant association was found with orchidectomy $(\mathrm{p}=0.473)$.

\section{Negative Exploration Group}

Table 4: History, clinical and operative findings in non-torsion group $(n=86)$.

\begin{tabular}{|c|c|}
\hline Clinical Finding & Number and Incidence \\
\hline Mean Age & $11.4 \mathrm{y}$ \\
\hline Pain site & $52(60 \%)$ \\
\hline Left & $34(40 \%)$ \\
\hline Right & \\
\hline Duration of pain & $16(19 \%)$ \\
\hline$<6$ hours & $34(39 \%)$ \\
\hline 6 to $\leq 12$ hours & $32(37 \%)$ \\
\hline 12 to $\leq 24$ hours & $4(5 \%)$ \\
\hline$>24$ hours & $38(83 \%)$ \\
\hline Pubertal/Adults & $2(2 \%)$ \\
\hline Vomiting & $2(2 \%)$ \\
\hline Pubertal/Adults who were & $45(52 \%)$ \\
\hline vomiting & $5(6 \%)$ \\
\hline Tender testis & $19(22 \%)$ \\
\hline Abnormal Dipstick & $5(6 \%)$ \\
\hline Abdominal pain & $6(7 \%)$ \\
\hline Abnormal cremasteric reflex & $56(65 \%$ \\
\hline High lying testis & \\
\hline Erythema & \\
\hline $86(65 \%)$ & \\
\hline
\end{tabular}

$86(65 \%)$ did not have evidence of testicular torsion at the time of exploration. The median age was 11 years (Range 1-25 years), Table 4. Less than 6-hour duration pain was seen in $16(18.6 \%), 34(39.5 \%)$ in $6-12$-hour group, $32(37.2 \%)$ in 12-24-hour group and $4(4.6 \%)$ in more than 24-hour group. Two $(2.6 \%)$ had vomiting and both patients had obstructed inguinal hernia. None of the patients underwent orchidectomy or orchidopexy. 


\section{Discussion}

In our study, the commonest pathology causing acute scrotum was not TT. A negative exploration rate of $65 \%$ is reported. Previous studies have reported TT to be present in up to $25 \%$ of cases of acute scrotum which is lower with our findings of 35\% [2]. Sudden pain was present in all cases of TT, however a majority had similar symptoms with other scrotal/ testicular aetiologies such as torsion of testicular appendage and epididymoorchitis. Therefore, relying on pain alone as a predictor of TT is unwise. An interesting point was significant association of vomiting with acute scrotal pain as a predictor of TT. This was even more pronounced when puberty or adolescent boys were taken into consideration who had TT. Interestingly, our results included 2 false positives who had vomiting because of obstructed inguinal hernia. Both of these patients had history of inguinal scrotal swelling in the past with a short duration of acute pain. If those two cases are excluded, then specificity ( $95 \%$ CI: $96-100 \%$ ) and positive predictive value approach $100 \%$ ( $\mathrm{p}<$ 0.0001 ) with an accuracy of $90 \%$ making it exceedingly reliable sign to diagnose TT.

More than one third of the patients lost a testis. Most of the operation notes did not make a mention of degree of twist of spermatic cord which is an independent important risk factor for testicular viability, therefore we had to rely on available data of time duration of acute scrotum alone. In our study time to theatre had no significant association with orchidectomy rates ( $p=0.473$ ), although in the time to get to theatre was less than 1 hour in all cases. 17(94\%) testes were salvaged in less than 6 hour-pain-period with only one $(5 \%)$ orchidectomy in this group followed by 6-12 hour-pain-duration group in which 8 $(73 \%)$ were salvaged and 3(27\%) were lost. In 12-24 hour-painduration group, 3(43\%) were salvaged and $4(57 \%)$ were lost. Lastly, in more than 24-hour group 2(20\%) testes were salvaged whereas $8(80 \%)$ resulted in an orchidectomy. Time of onset of symptoms to hospital presentation remains the crucial factor deciding whether testis is salvageable or not. The longer the symptoms worse is the prognosis.

As evident in our study, sudden pain was present in all cases of TT but also in majority of cases of THM. It had a low sensitivity and NPV at 30\% (95\% CI: 20.7-41.3\%) and 27.3\% (95\% CI: $17.7-$ $38.6 \%)$ respectively. It did have a high PPV of $100 \%$ (95\% CI: 85.7-100\%) since all our patients with TT had sudden onset testicular pain. On its own, sudden testicular pain may not be very best of the symptoms to predict TT but its absence means diagnosis of TT is unlikely. More than two thirds of patients with TT had at least a single episode of vomiting. This was however also present in two patients who did not have TT but were diagnosed with incarcerated inguinal hernia. It had reasonably good sensitivity of $75 \%$ (95\% CI: $53.3-90.2 \%$ ) and positive predictive value of $90 \%$ (95\% CI: $68.3-98.7 \%$ ). The negative predictive value was $92.6 \%$ (95\% CI: 84.6-97.2\%) making it an important symptom when considering diagnosis of TT.
Another extremely important finding was that pubertal boys tended to vomit when they had TT, whereas younger patients lacked this symptom making it a very unique finding. In our study, 19 (79.1\%) out of 24 patients who had TT, were either pubertal or adults - out of them 18 (94.7\%) had at least a single episode of vomiting making it an extremely specific sign when considering scrotal exploration. The positive predictive value was $100 \%(81.5-100 \%)$ and negative predictive value was $92.7 \%$ (95\% CI: 85-97.3\%). Given the challenge facing primary care physicians and emergency department doctors in accurately and promptly diagnosing patients with TT due to the wide differential diagnosis- these key findings may assist their diagnosis. It may also reduce the negative exploration rates.

The implications of a missed torsion carry serious consequences- the loss of a testis with potential impaired fertility and sperm counts [19]. It is also the third most common cause of litigation in adolescent males [20]- as a result many surgical units explore all cases of acute scrotum- however this approach carries the risks of anesthesia related complications and negative explorations- as was seen in 86 patients (65\%) of our series. Some studies have attempted to develop scoring systems as a clinical aid to accurately diagnosing TT $[4,18]$. Boettcher et al. developed a scoring system involving four key parameters- duration of pain ( $<24$ hours), nausea/vomiting, high testicular position and abnormal cremasteric reflex. TT was predicted if at least one of the four symptoms were present. Application of their scoring system would have reduced their negative exploration rate by $55 \%$ and not missed a case of TT in their series [18]. In their series, vomiting was associated with a high odds ratio (22.5, CI 95\%: 2.9-217) of predicting TT.

Barbosa et al., as part of the TWIST (Testicular Workup for Ischemia and Suspected Torsion) study, developed a scoring system for risk stratification regarding the diagnosis of TT. The prediction model featured testicular swelling ( 2 points), hard testis on palpation ( 2 points), nausea/vomiting ( 1 point), high riding testis ( 1 point) and absent cremasteric reflex (1 point). A score of 2 or less corresponded to low risk of TT with no recommendation of ultrasound (US). A score of 3 or 4 determined an intermediaterisk ofTT, for which US was recommended. A score of 5 or more identified a high risk of TT with recommendation of surgical exploration. They demonstrated that the use of this risk stratification could have reduced the number of US performed by $80 \%$ and more than $50 \%$ of cases could have ischemia times reduced by going direct to exploration [4]. Nevertheless, we are slow to advocate a scoring system in our institution, we promote a high index of suspicion for TT in any patient presenting with an acute scrotum regardless of associated symptoms. This can lead to negative explorations as was seen in more than two third of patients explored in our series- however we feel the benefits outweigh the risks of a missed torsion and do not recommend delaying exploration due to imaging.

In our institutions, DUSS is performed by radiologists but not available 24 hours a day and not standard for patients presenting 
with acute scrotum. Given the challenge associated with accurately diagnosing TT solely based on history and physical examination- the addition of an easily available test which would achieve a higher diagnostic yield would be of great benefit to patients and clinicians. DUSS in trained hands has previously been shown to have high sensitivity and predictive values $[7,21,22]$ however it is user dependent and is well documented that there is a degree of error and inaccuracy involved $[23,24]$. False positive findings demonstrating central perfusion may be attributable to the special vascular supply to the testis. Even after de-torsion, a necrotic testis can show a certain amount of central perfusion, mimicking viable testis [20].

\section{Conclusion}

Our study demonstrated TT to comprise $34.8 \%$ of all acute scrotum cases and this was affecting mostly pubertal or adolescent boys. Patients who vomited were 14 times more likely to have TT than to those who did not (RR 13.8, 95\% CI: 6.4-30). The combination of vomiting and testicular pain should heighten suspicion for TT.

\section{References}

1. Karaguzel E, Kadihasanoglu M, Kutlu O (2014) Mechanisms of testicular torsion and potential protective agents. Nat Rev Urol 11(7): 391399.

2. Zhao LC, Lautz TB, Meeks JJ, Maizels M (2011) Pediatric testicular torsion epidemiology using a national database: incidence, risk of orchidectomy and possible measures toward improving the quality of care J Urol 186(5): 2009-2013.

3. Liang T, Metcalfe P, Sevcik W, Noga M (2013) Retrospective review of diagnosis and treatment in children presenting to the pediatric department with acute scrotum. AJR AM J Rentgenol 200(5): W444-W449.

4. Barbosa JA, Tiseo BC, Barayan GA, Rosman BM, Torricelli FC, et al. (2013) Development and initial validation of a scoring system to diagnose testicular torsion in children. J Urol 189(5): 1859-1864.

5. Johnston JW, Larsen P, El-Haddawi FH, Fancourt MW, Farrant GJ, et al. (2015) Time delays in presentation and treatment of acute scotal pain in a provincial hospital. ANZ J Surg 85(5): 330-333.

6. Ubee SS, Hopkinson V, Srirangam SJ (2014) Parental perception of acute scrotal pain in children. Ann R Coll Surg Engl 96(8): 618-620.

7. Ciftci AO, Senocak ME, Tanyel FC, Buyukpamukcu N (2004) Clinical predictors for the differential diagnosis of acute scrotum. Eur J Pediatr Surg 14(5): 333-338.

8. Srinivasan A, Cinman N, Feber KM, Gitlin J, Palmer LS (2011) History and physical examination findings predictive of testicular torsion:

This work is licensed under Creative

Commons Attribution 4.0 License

DOI: 10.19080/JOJUN.2019.06.555689 an attempt to promote clinical diagnosis by house staff. J Pediatr Urol 7(4): 470-474.

9. Molokwu CN, Somani BK, Goodman CM (2011) Outcomes of scrotal exploration for acute scrotal pain suspicious for testicular torsion: a consecutive case series of 173 patients. BJU Int 107(6): 990-993.

10. Boettcher M, Bergholz R, Krebs TF, Wenke K, Aronson DC (2012) Clinical predictors of testicular torsion in children. Urology 79(3): 670-674.

11. Baker LA, Sigman D, Matthews RI, Benson J, Docimo SG (2000) An analysis of clinical outcomes using color Doppler testicular ultrasound for testicular torsion. Pediatrics 105(3 pt 1): 604-607.

12. Yagil Y, Naroditsky I, Milhem J, Leiba R, Leiderman M, Badaan S et al. (2010) Role of Doppler ultrasonography in the triage of acute scrotum in the emergency department. J Ultrasoun Med 29(1): 11-21.

13. Yang C Jr, Song B, Liu X, Wei GH, Lin T, He DW (2011) Acute scrotum in children: an 18-year retrospective study. Pediatr Emerg Care 27(4): 270-274.

14. Bartsch G, Frank S, Marberger H, Mikuz G (1980) Testicular torsion: late results with special regard to fertility and endocrine function. J Urol 124(3): 375-378.

15. Makela E, Lahdes-VT, Rajakorpi H, Wilkstrom S (2007) A 19-year review of pediatric patients with acute scrotum. Scan J Surg 96(1): 62-66.

16. Kapoor S (2008) Testicular torsion: a race against time. Int J Clin Pract 62(5): 821-827.

17. Gatti JM, Patrick Murphy J (2007) Current management of the acute scrotum. Semin Pediatr Surg 16(1): 58-63.

18. Boettcher M, Krebs T, Bergholz R, Wenke K, Aronson D, Reinshagen K (2013) Clinical and sonographic features predict testicular torsion in children: a prospective study. BJU Int 112(8): 1201-1206.

19. Mansbach JM, Forbes P, Peters C (2005) Testicular torsion and risk factors for orchidectomy. Arch Pediatr Adolesc Med. 159: 1167-1171.

20. Selbst SM, Friedman MJ, Singh SB (2005) Epidemiology and etiology of malpractice lawsuits involving children in US emergency departments and urgent care centers. Pediatr Emerg Care 21(3): 165-169.

21. Nason GJ, Tareen F, McLoughlin D, McDowell D, Cianci F, Mortell A (2013) Scrotal exploration for acute scrotal pain: a 10 year experience in two tertiary referral paediatric units. Scand J Urol 47(5): 418-422.

22. Waldert M, Klatte T, Schmidbauer J, Remzi M, Lackner J, Marberger M (2010) Color Doppler sonography reliably identifies testicular torsion in boys. Urology 75(5): 1170-1174.

23. Gunther P, Schenk JP, Wunsch R, Holland-CS, Kessler U, Troger J, et al. (2006) Acute testicular torsion in children: the role of sonography in the diagnostic workup. Eur Radiol 16(11): 2527-2532.

24. Lam WW, Yap TL, Jacobsen AS, Teo HJ (2005) Color Doppler ultrasonography replacing surgical exploration for acute scrotum: myth or reality? Pediatr Radiol 35(6): 597-600.

\section{Your next submission with Juniper Publishers} will reach you the below assets

- Quality Editorial service

- Swift Peer Review

- Reprints availability

- E-prints Service

- Manuscript Podcast for convenient understanding

- Global attainment for your research

- Manuscript accessibility in different formats

( Pdf, E-pub, Full Text, Audio)

- Unceasing customer service

Track the below URL for one-step submission

https://juniperpublishers.com/online-submission.php 